OPEN ACCESS

Edited by: Ronnel B. King,

University of Macau, China

Reviewed by:

Kimmo Eriksson,

Mälardalen University College,

Sweden

Elmer Dela Rosa,

Central Luzon State University,

Philippines

*Correspondence:

Frédéric Guay

Frederic.Guay@fse.ulaval.ca

Specialty section

This article was submitted to

Educational Psychology,

a section of the journal

Frontiers in Psychology

Received: 07 July 2020 Accepted: 16 September 2021 Published: 18 October 2021

Citation:

Supper W, Guay F and Talbot D (2021) The Relation Between Television Viewing Time and Reading Achievement in Elementary School

Children: A Test of Substitution and Inhibition Hypotheses.

Front. Psychol. 12:580763.

doi: 10.3389/fpsyg.2021.580763

\section{The Relation Between Television Viewing Time and Reading Achievement in Elementary School Children: A Test of Substitution and Inhibition Hypotheses}

\author{
Wilfried Supper ${ }^{1}$, Frédéric Guay ${ }^{1 *}$ and Denis Talbot ${ }^{2}$ \\ ${ }^{1}$ Département des fondements et pratiques en éducation, Faculté des sciences de l'éducation, Université Laval, Quebec, \\ QC, Canada, ${ }^{2}$ Département de médecine sociale et préventive, Faculté de Médecine, Université Laval, Quebec, QC, \\ Canada
}

Research has focused on the relations between television (TV) viewing time and children's reading achievement. Two hypotheses have been proposed to explain this relation. The substitution hypothesis proposes that TV viewing distracts students from activities that are important for their learning. The inhibition hypothesis proposes that watching television inhibits important affective/cognitive skills. In this study, we test both hypotheses by estimating the relation between TV viewing time and reading achievement. We use the frequency of students' leisure reading and the frequency of interactions between students and their parents as potential mediators to test the substitution hypothesis, whereas for the inhibition one, we use students' intrinsic motivation to read and their level of inattention. Data come from the Québec Longitudinal Study of Child Development (QLSCD). Designed by the Institut de la statistique $d u$ Québec, QLSCD covers a wide range of themes. The QLSCD is representative of children in Québec and contains 2223 participants who were followed from 0 to 21 years old. The four structural models tested are built as follows: the TV viewing time at 6 years old predicts the four mediating variables at 8 years old, which in turn predicts reading achievement at 10 years old. In addition, we have tested models' gender invariance. Results indicate that TV viewing time is not directly or indirectly associated with reading achievement. Specifically, it is not associated with the mediating variables of child-parent interactions, intrinsic motivation, and inattention. However, the frequency of leisure reading is negatively associated with the time spent watching TV. This association is very small $(-0.07)$ and has no indirect effect on reading achievement. Finally, results do not vary according to the gender of the participants. Our results are in line with those of previous studies in the field and cast some doubts on the potential negative effects of $T V$ viewing time on reading achievement.

Keywords: television viewing time, reading achievement, reading for leisure, intrinsic motivation, inattention 


\section{INTRODUCTION}

Television (TV) viewing time has been widely criticized for its negative influence on children's learning to read (Winn, 1977; Postman, 1986; Ennemoser and Schneider, 2007). Major concerns are that time spent on watching TV replaces reading activities, reduces children's interest for reading, lowers language skills, makes children intellectually lazy, inattentive, and inhibits their imagination (Himmelweit et al., 1958; Winn, 1977; Hornik, 1981; Postman, 1986; Popper et al., 1995; Ennemoser and Schneider, 2007; Desmurget, 2011). In addition, the important portion of time children devote to this leisure activity might be a cause of concern. Indeed, several studies reveal that, on average, children spend as much time watching TV, as they do performing classroom tasks (Paik, 2000; Desmurget, 2011). This makes TV watching one of the most frequent hobbies for a majority of children (Rideout, 2016). It is therefore important to identify the extent to which the time spent watching TV affects children's reading achievement (RA). For more than 60 years, research has focused on this relation. However, very few studies have investigated the processes that explain why TV viewing has been associated with lower RA. Among studies testing mediators, results are divergent (Kostyrka-Allchorne et al., 2017; Supper et al., in-press article). Researchers have proposed several hypotheses to explain this divergence, including content type (Wright et al., 2001; Ennemoser and Schneider, 2007), cultural differences (Ennemoser and Schneider, 2007), differences in methodological quality between studies (Zavodny, 2006; Gentzkow and Shapiro, 2008; Munasib and Bhattacharya, 2010), the existence of moderators (Paik, 2000; Razel, 2001), and a non-linear relationship (Paik, 2000; Razel, 2001; Huang and Lee, 2010). However, studies that have focused on these potential confounding effects also show conflicting results (for research that specifically addresses this topic, see: Kostyrka-Allchorne et al., 2017; Supper et al., 2021). For example, cultural differences or content differences are aspects that we feel are secondary to consider in order to better understand this divergence in results. Indeed, most hypotheses on TV viewing time and RA are based on the video format of the TV and not on the type of content or messages likely to be broadcasted. Simply watching more TV is expected to predict a decrease in the amount of time children spend on educational activities such as reading, regardless of the type of program shown or the cultural practices between children in different countries. Based on past research, it is therefore difficult to draw clear conclusions about how TV viewing time is associated with RA.

\section{Hypotheses Explaining the Negative Effects of Television Watching Time on Reading Achievement}

Researchers propose several processes to explain why TV watching time could be negatively associated with RA (Himmelweit et al., 1958; Schramm, 1961; Hornik, 1981; Beentjes and Van der Voort, 1988). These processes can be classified into the substitution and the inhibition hypotheses.
The substitution hypothesis posits that the time children spend watching TV replaces the time they spend on other activities more susceptible to enhance their RA, such as reading, writing, and doing schoolwork (Hornik, 1981). This hypothesis therefore assumes that the different activities that make up children's schedules reflect a zero-sum game (Peaucelle, 1969). That is, an increase in the time spent on one type of activity, for example watching TV, inevitably decreases the time devoted to other types of activities favorable to RA. Among these educative activities, the frequencies of leisure reading and of non-educational interactions between children and their parents seem to be relevant mediating variables for testing the substitution hypothesis.

Leisure reading helps children to provide cognitive efforts when needed, to mobilize reading strategies learned in school, to discipline themselves, and to solve problems (Bergin, 1992). Thus, a decrease in the time that children spend on leisure reading will result in less time spent on cognitive, behavioral, and affective processes that enhance their RA. For this reason, we have chosen leisure reading as a mediating variable to test the substitution hypothesis. Some studies conclude that the time spent watching TV is associated with a decrease in leisure reading time (Koolstra et al., 1996; Shin, 2004; Ennemoser and Schneider, 2007), while other studies indicate that there is no association between these two variables (Himmelweit et al., 1958; Schramm, 1961; Ritchie et al., 1987; Anderson et al., 2001; Wright et al., 2001).

Furthermore, children who watch more TV could deprive themselves from the positive effects of spending time with their parents, such as better language development (Zimmerman et al., 2009) or support for their academic success (Guay et al., 2007). Indeed, TV watching time is associated with fewer parent-child interactions (Zimmerman et al., 2007). Television viewing time is also associated with a decrease in time spent on homeworks (Johnson et al., 2007), which are usually supervised by parents. However, some studies do not support these negative relationships (Schramm, 1961; Nakamuro et al., 2013).

The inhibition hypothesis posits that watching TV negatively affects RA by altering certain cognitive (mainly attention and concentration) or affective components (mainly valuing effort and interest in reading and school learning; Himmelweit et al., 1958; Beentjes and Van der Voort, 1988). The rationale underlying this hypothesis is that TV broadcasts content that does not require a sustained effort of understanding or concentration (Hornik, 1981). In addition, the images' speed, the quality of the visual and sound effects and the abundant supply of channels make this content entertaining and very stimulating, which gives children pleasure from the very first minutes (Winn, 1977; Postman, 1986). Thus, immediate and easy access to an entertaining activity could lead children to develop a certain "mental laziness" (Himmelweit et al., 1958; Beentjes and Van der Voort, 1988) which would discourage them from mobilizing efforts or concentration to be interested in reading activities. Intrinsic motivation (IM) to read, that is reading for the sole interest or pleasure it provides (Ryan and Deci, 2000), could therefore be negatively affected by the number of hours children spend watching TV. It is well known that a decrease 
in IM to read is associated with a decrease in cognitive and emotional commitment to reading (Guthrie et al., 2012), in reading comprehension (Malanchini et al., 2017), in perceived reading skills and in RA (Morgan and Fuchs, 2007). For this reason, we have chosen IM to read as a mediating variable to test the inhibition hypothesis. In line with this, one study suggests that TV viewing is negatively associated with favorable attitudes toward reading (a concept similar to IM; Koolstra et al., 1996) or with reading motivation (Anderson et al., 2001), while another concludes that these variables are not significantly linked (Ennemoser and Schneider, 2007).

In addition, when asked to perform less interesting educational activities, children who watch a lot of TV may find it difficult to sustain their attention and, as a result, become more easily distracted (Beentjes and Van der Voort, 1988). An increase in inattention is associated with a decrease in RA (Rabiner et al., 2000). For this reason, we selected "attention" as an additional mediating variable to test the inhibition hypothesis. In this regard, the majority of studies indicate that watching TV is associated with an increase in inattention (Christakis et al., 2004; Mehmet-Radji, 2004; Acevedo-Polakovich et al., 2006; Johnson et al., 2007; Miller et al., 2007; Maass et al., 2010; Swing et al., 2010; Schmiedeler et al., 2014). However, an important number of studies have also found that there is no association between these variables (see Table 1).

In conclusion, the four mediating variables we chose to test the substitution and inhibition hypothesis are leisure reading, parent-child interaction, IM to read, and inattention. These mediators were chosen because they seem to be the ones that best fit the propositions of these two hypotheses (Hornik, 1981; Beentjes and Van der Voort, 1988; Koolstra et al., 1996; Ennemoser and Schneider, 2007).

\section{Children's Age}

The vast majority of children start watching TV long before they reach the age when they learn to read. Therefore, by the time these children begin to learn to read at school, they have developed the habit of watching TV frequently and then have potentially developed cognitive and affective components that could hamper their willingness to engage in more demanding activities, such as reading (Hornik, 1981; Beentjes and Van der Voort, 1988; Ennemoser and Schneider, 2007). Thus, it is relevant to test the inhibition and substitution hypotheses early in children's development.

\section{Children's Gender as a Potential Moderator}

Testing gender as a potential moderator is important for several reasons. First, boys watch TV for longer periods than girls (Sisson et al., 2012). They are exposed to more violent content and shows that portray stereotypical representations of masculinity (Coyne et al., 2014). These TV shows are thus more likely to provide the viewer with greater visual stimulation, and may thereby make boys more susceptible to inhibition effects. Second, the majority of children have female reader models (Morin, 2014) and boys more frequently report that reading is a female activity (Clark,
2012). This stereotypical view of reading could lead boys to value this activity less and thus to be less interested in reading (Morin, 2014). Third, boys read less frequently for leisure (Morin, 2014) and their book choices are more circumscribed around comic books (Morin, 2014). Boys therefore read more pictorial books, and choose more frequently reading formats that are close to TV content. For this reason, the type of reading that boys prefer may be more easily replaced by TV content. These gender differences may thus moderate the relationship between TV viewing time and RA. In light of the above, we expected the following: for boys, the relationships connecting TV viewing to the mediators and RA should be stronger than those observed for girls. In other words, boys would be more prone to the inhibition and substitution effects.

\section{Contributions of This Study}

This study contributes to the existing literature in several ways. First, no study has tested the moderating role of gender in the "TV $\rightarrow$ mediators $\rightarrow$ RA" sequence. Second, studies that have tested the relationship between TV viewing time and some mediating variables show contrasting results. It is therefore difficult to determine whether watching TV is associated with less leisure reading or increased inattention. Yet, according to studies testing the relationship between TV viewing and RA (Hornik, 1981; Beentjes and Van der Voort, 1988), these two variables are among those that allow the inhibition and substitution hypotheses to be tested in the most stringent way. Third, few studies have tested substitution and inhibition hypotheses simultaneously, aside from the one conducted by Ennemoser and Schneider (2007). However, this study has important limitations. On the one hand, the results presented are unclear and they are divided between those indicating that TV viewing time is negatively associated with RA and those revealing that there is no association between these variables. On the other hand, this study contains a very limited number of participants. It is therefore important to test the substitution and inhibition hypothesis with a larger representative sample. Indeed, it was important to conduct such research, both socially and scientifically. It allows for a more precise estimation of how TV viewing time is related to RA and, therefore, for more appropriate recommendations and interventions. For example, if TV viewing time decreased leisure time spent reading, but did not inhibit cognitive abilities, parents could ensure that viewing time does not interfere with their children's reading time. Conversely, if TV viewing time were not related to reading time, but was related to language development, then it would be important to recommend a more systematic reduction in TV viewing time, especially for younger children. Testing these two hypotheses together, therefore, provides a better understanding of the relationship between TV viewing time and RA. Fourth, longitudinal studies testing IM to read and the frequency of parent-to-child interactions as mediating mechanisms in the "TV $\rightarrow$ RA" relationship are scarce.

\section{Goals and Hypotheses}

The goal of this study is to better understand the processes likely to mediate the relationship between TV viewing time and children's RA. In order to test the inhibition and substitution 
TABLE 1 | Studies on the association between TV viewing time and mediating variables.

\begin{tabular}{|c|c|c|c|}
\hline Authors & Year & Mediator & Results \\
\hline Tomopoulos et al. & 2010 & Cognitive skills & Negative association \\
\hline Lonner et al. & 1985 & Cognitive skills & NS \\
\hline Acevedo-Polakovich et al. & 2006 & Attention & Negative association \\
\hline Cheng et al. & 2010 & Attention & Negative association \\
\hline Christakis et al. & 2004 & Attention & Negative association \\
\hline Maass et al. & 2010 & Attention & Negative association \\
\hline Mehmet-Radji & 2004 & Attention & Negative association \\
\hline Miller et al. & 2007 & Attention & Negative association \\
\hline Schmiedeler et al. & 2014 & Attention & Negative association \\
\hline Swing et al. & 2010 & Attention & Negative association \\
\hline Johnson. Cohen et al. & 2007 & Attention & Negative association \\
\hline Ansari and Crosnoe & 2016 & Attention & NS \\
\hline Foster and Watkins & 2010 & Attention & NS \\
\hline Landhuis et al. & 2007 & Attention & NS \\
\hline Parkes et al. & 2013 & Attention & NS \\
\hline Stevens et al. & 2009 & Attention & NS \\
\hline Stevens et Mulsow & 2006 & Attention & NS \\
\hline Zimmerman and Christakis & 2007 & Attention & NS \\
\hline Koolstra et al. & 1996 & Attitude toward reading/Leisure reading & Negative association \\
\hline Ennemoser and Schneider & 2007 & Attitude toward reading & NS \\
\hline Johnson et al. & 2007 & Negative attitude toward school & Negative association \\
\hline Huang \& Lee & 2010 & Negative behavior at school & Negative association \\
\hline Nakamuro et al. & 2013 & Negative behavior at school & NS \\
\hline Parkes et al. & 2013 & Negative behavior at school & NS \\
\hline Zimmerman et al. & 2007 & Language development & Negative association \\
\hline Tomopoulos et al. & 2010 & Language development & Negative association \\
\hline Barr et al. & 2010 & Language development & Negative association \\
\hline Blankson et al. & 2015 & Language development & NS \\
\hline Duch et al. & 2013 & Language development & Negative association \\
\hline Schmidt et al. & 2009 & Language development & NS \\
\hline Ruangdaraganon et al. & 2009 & Language development & Negative association \\
\hline Pagani et al. & 2013 & Language development & Negative association \\
\hline Linebarger et al., & 2005 & Language development & Negative association \\
\hline Bittman et al. & 2011 & Language development & NS \\
\hline Johnson et al. & 2007 & Homework & Negative association \\
\hline Nakamuro et al. & 2013 & Homework & NS \\
\hline Koolstra et al. & 1997 & Mental effort & Negative association \\
\hline Barr et al. & 2010 & Executive functions & Negative association \\
\hline Hamer et al. & 2010 & Cognitive functions & Negative association \\
\hline Ennemoser and Schneider & 2007 & Reading & Negative association \\
\hline Anderson et al. & 2001 & Motivation & NS \\
\hline Sharif et al. & 2010 & Search for sensation & Negative association \\
\hline Blankson et al. & 2015 & Numeracy skills test & NS \\
\hline Schmidt et al. & 2009 & Visual motor skills & NS \\
\hline
\end{tabular}

NS $=$ Not statistically significant at the $5 \%$ level.

hypotheses, we will explore if the time that 6-year-old children spend watching TV predicts the frequency of their leisure reading, the frequency of their interaction with their parents, their IM to read and the level of inattention at the age of 8 . Additionally, we will test if, in turn, these four variables predict their RA at the age of 10 . If the substitution hypothesis is supported, the TV viewing time at 6 years old will be negatively associated with the frequency of their leisure reading and/or the frequency of their interaction with the parent at 8 years old. If the inhibition hypothesis is corroborated, then TV viewing time at 6 years of age will be negatively associated with IM to read at 8 years of age and/or will be positively associated with inattention at 8 years of age. Finally, we posit that boys are more likely than girls to be affected by substitution and 
inhibition effects: at equal TV viewing time, we expect the substitution and inhibition effects will be more marked for boys than for girls.

\section{MATERIALS AND METHODS}

\section{Participants}

The data came from the Québec Longitudinal Study of Child Development (QLSCD). The QLSCD targeted the population of children who were born in Québec between 1997 and 1998. However, children living on Indigenous reserves, regions of Nord-du-Québec, Cree territory and Inuit territory as well as children born prematurely (gestation less than 24 weeks) were excluded (Jetté and Des Groseilliers, 2000).

Québec longitudinal study of child development contained data concerning 2223 children aged between 5 and 6 months at the time of recruitment. This sample was made up of $48.8 \%$ of females. Since young children could not have answered the various measures themselves, the QLSCD has asked parents or legal guardians to complete the measures. Mother is the "Person Most Knowledgeable» (PMK) of children's behaviors in 98.4\% of cases. To obtain a better consistency, the QLSCD has encouraged the PMK to be the same respondent over time. In terms of education level, $44 \%$ of PMKs and $28 \%$ of fathers held a high school diploma or did not have a diploma, 29\% of the PMK and $41 \%$ of fathers had a non-university post-secondary diploma and $26 \%$ of PMK and $30 \%$ of fathers had a university degree. Furthermore, $86.5 \%$ of mothers and $84.5 \%$ of fathers were Québec natives. Finally, French was the mother tongue for most of the participants' mothers (81\%), followed by English (9\%) and other languages (10\%).

The variables used to test our hypotheses were measured at the ages of 5 months, and 6, 7, 8, and 10 years old. In Table 2, we have indicated the measurement times during at which each variable was measured.

\section{Measures}

\section{The Average Daily Television Viewing Time}

This variable was assessed by the PMK, when the child was 6 years old. The following questions were asked: "How much time does your child spend watching TV during the week?" and "How much time does your child spend watching TV during the weekend?" These two questions came from the Canadian Community Health Survey. This measure was similar to measures of TV viewing time used in other surveys (e.g., the National Longitudinal Survey of Children). The average TV viewing time per day for 6 years-old in the QLSCD was $1 \mathrm{~h}$ and $50 \mathrm{~min}$. This amount is comparable to the average in other surveys (Zimmerman and Christakis, 2005; Rideout, 2016).

\section{Academic Reading Achievement}

This variable was assessed by teachers. In this study, we have selected scores when the children were 7 years old and when they were 10 years old. Scores on RA were strongly correlated with other measures of academic performance (see Forget-Dubois et al., 2007). The teacher has reported children's RA by answering the following question: "How would you assess the child's current academic success in reading?" The answers were given on a scale from 1 to 5 : $(1=$ among the first in the class; $5=$ among the last in the class). Students' scores were assessed at the end of the school year.

\section{The Frequency of Leisure Reading}

This measure came from the PMK's response to the question: "How often does your child enjoy reading?" This variable has been assessed when the child was 6 years old and when the child was 8 years old. Answers were rated on a scale from 1 to 7 ( 1 = rarely or never; $4=$ a few times a month; $7=$ every day). Previous studies showed that this measure of reading time for leisure was associated with children's RA at 8 years old (Tétreault and Desrosiers, 2014; Nanhou et al., 2016; Torppa et al., 2020; Manu et al., 2021).

\section{Frequency of Non-educational Interactions Between the Child and the Parent}

This scale was filled by the PMK. For our study, we used the responses that were provided when the child was 6 years old and when the child was 8 years old. This scale was adapted from a subscale of the Parenting Practices Scale by Strayhorn and Weidman (1988; Boivin et al., 2000) which aimed to measure the frequency of supportive and encouraging behaviors from parent to child. This scale presented an acceptable level of validity and fidelity (Strayhorn and Weidman, 1988; Boivin et al., 2000; Verhoeven et al., 2010). It includes 10 items when the child was 6 years old and 5 items when the child was 8 years old. To measure the frequency of non-educational interactions between the child and the parent, we only kept three items per measurement time: "How often do you talk or play with the child?"; "How often do you do a special activity that she/he enjoys?"; "How often do you get involved in sports, hobbies or games?". Answers were given on a scale from 1 to 5 ( $1=$ never; $5=$ several times a day). Other items on this scale were excluded for two reasons. First, the removed items mainly measured the quality of parenting practices rather than the frequency of parent-child interactions (i.e.,: "In the past 12 months, when you talked to the child about behavior, in what proportion of the time did you congratulate?"). However, our substitution hypothesis targeted the frequency of interactions and not their quality. The exclusion of items that did not measure the frequency of interactions therefore allowed us to be more consistent with our hypothesis. Second, the three items that were selected are identical between the 2 measurement times. The internal consistency of our three items was 0.61 when the child was 6 years old and 0.63 when the child was 8 years old (Cronbach's alpha).

\section{Intrinsic Motivation for School Reading}

This measure came from a scale that was filled by the child at 7 and 8 years old. Items were from a subscale of the "Elementary School Motivation Scale" (Guay et al., 2010) whose aim was to measure different forms of school motivation in reading, writing and mathematics for a population of elementary school children. The content validity, construct validity, and internal consistency of the scale has been supported (Guay et al., 2010). The IM for 
TABLE 2 | Descriptive statistics.

\begin{tabular}{|c|c|c|c|c|c|c|c|c|}
\hline & \multicolumn{2}{|c|}{ Girls } & \multicolumn{2}{|c|}{ Boys } & \multicolumn{4}{|c|}{ Total population } \\
\hline & Mean & SD & Mean & SD & Mean & SD & Attrition & Age (years) \\
\hline Parental practices & 4.6 & 0.8 & 4.6 & 0.8 & 4.6 & 0.8 & $33.0 \%$ & 6 \\
\hline Parental practices & 4.3 & 0.8 & 4.4 & 0.9 & 4.4 & 0.9 & $34.8 \%$ & 8 \\
\hline Inattention & 1.3 & 0.4 & 1.5 & 0.5 & 1.4 & 0.5 & $47.6 \%$ & 7 \\
\hline Inattention & 1.3 & 0.4 & 1.5 & 0.5 & 1.4 & 0.5 & $49.7 \%$ & 8 \\
\hline Talk about school activities a & 6.9 & 0.4 & 6.9 & 0.5 & 6.9 & 0.5 & $31.5 \%$ & 8 \\
\hline $\mathrm{IQ}$ & 80.5 & 17.4 & 80.2 & 16.9 & 80.4 & 17.2 & $47.6 \%$ & 6 \\
\hline Parental valorization of grades & 3.5 & 0.6 & 3.5 & 0.6 & 3.5 & 0.6 & $31.7 \%$ & 8 \\
\hline Leisure reading & 5.3 & 2.0 & 4.5 & 2.2 & 4.9 & 2.2 & $42.7 \%$ & 7 \\
\hline Leisure reading & 4.3 & 1.0 & 3.8 & 1.3 & 4.1 & 1.1 & $43.2 \%$ & 9 \\
\hline Motivation to read & 4.3 & 0.8 & 4.0 & 1.0 & 4.1 & 0.9 & $34.4 \%$ & 8 \\
\hline Motivation to read & 4.3 & 0.8 & 4.0 & 1.0 & 4.1 & 0.9 & $34.4 \%$ & 9 \\
\hline Reading score & 3.7 & 1.3 & 3.4 & 1.4 & 3.5 & 1.3 & $42.1 \%$ & 7 \\
\hline Reading score & 3.6 & 1.2 & 3.2 & 1.3 & 3.4 & 1.3 & $57.2 \%$ & 11 \\
\hline PMK diploma & 2.7 & 1.1 & 2.7 & 1.0 & 2.7 & 1.1 & $0.1 \%$ & 0.4 \\
\hline TV viewing time & 1.8 & 0.9 & 1.9 & 0.8 & 1.8 & 0.8 & $33.0 \%$ & 6 \\
\hline Gender & 1 & 0 & 0 & 0 & 0.5 & 0.0 & $0.0 \%$ & 0.4 \\
\hline
\end{tabular}

Motivation, parental practices and inattention variables are items means corresponding to these constructs.

school reading was made up of 3 items ("I like reading"; "Reading interests me a lot"; "I read even when I don't have to") for which the answers were given on a scale from 1 to 4 ( 1 = always no, sometimes no, sometimes yes, 4 = always yes). In QLSCD, Cronbach's alpha was 0.68 when the child was 7 years old and 0.68 at 8 years old.

\section{Children's Symptoms of Inattention}

This measure was filled out by the teacher when the child was 7 years old and when the child was 8 years old. The items on this scale came from the Ontario Child Health Study (OCHS; Cardin et al., 2011). This scale had a good level of validity (Boyle et al., 1993; Romano et al., 2006; Cardin et al., 2011) and has been used in various studies for its ability to predict school achievement (Pingault et al., 2013). This scale was composed of 5 items ("was unable to concentrate"; "could not maintain her/his attention for a long time"; "was easily distracted"; "had difficulty pursuing any activity"; "was inattentive"). Answers were given on a scale from 1 to 3 ( 1 = never or not true; sometimes/a little; 3 = often or very). For two measurement times, when the child was 7 and 8 years old, the Cronbach's alpha was 0.88 .

\section{Control Variables}

Several authors have highlighted the important influence that confounding variables have on the relationship between TV viewing time and RA (Ennemoser and Schneider, 2007; Munasib and Bhattacharya, 2010). More specifically, the intelligence quotient (IQ), the level of education of the parents and the parental involvement determine both the time spent watching TV and the RA (Ennemoser and Schneider, 2007). Consequently, we controlled in our models the following four variables: parents' education level, child's IQ, parents' interest in their child's education and parents' valorization of good grades (Ennemoser and Schneider, 2007; Munasib and Bhattacharya, 2010).
Some authors also suggest that the time spent watching TV and the RA potentially have reciprocal relationships (Munasib and Bhattacharya, 2010). In order to minimize the influence of these biases, we controlled our mediating and dependent variables by taking into account initial scores on these variables.

In this study, we used four covariates to test our hypotheses. First, the highest level of education that the PMK has achieved was measured by a Likert scale from 1 to 4 ( 1 = no diploma; 4 = university degree). Second, the Peabody Picture Vocabulary Test was administered to the children when they were 6 years old (Dunn et al., 1993). This IQ test was strongly correlated with other measures of intelligence (Childers et al., 1994) and it was used in several studies that focus on RA (Salla et al., 2016). Scores could range between 1 and 120. Third, the frequency of PMK talking to the child about school activities was assessed by the following question: "How often do you talk to your child about school activities or work?" Responses were given on a scale from 1 to 4 ( 1 = daily; $4=$ rarely $)$. This variable was measured when the child was 7 years old. Fourth, the value of academic performance was the PMK's response to the question: "How important is it to you that your child has good grades in school?" This variable was associated with the child's RA (Tétreault and Desrosiers, 2014). The answer was given on a scale from 1 to 4 ( $1=$ very important; 4 = not important) and it was measured when the child was 7 years old.

\section{Statistical Analysis Missing Data}

The QLSCD contained a significant number of missing data as shown in Table 2. We treated these missing data with the "full information maximum likelihood" (FIML) procedure of Mplus (Muthén and Muthén, 2012). 
TABLE 3 | Fit indices for the 4 models with and without invariance test.

\begin{tabular}{|c|c|c|c|c|c|c|c|}
\hline & Npar & $x^{2}$ & dl & CFI & NNFI & RMSEA & {$[\mathrm{Cl}]$} \\
\hline Model for the whole population & 82 & $84.16^{\star}$ & 38 & 0.98 & 0.96 & 0.02 & {$[0.01,0.03]$} \\
\hline 2-Saturation (S) between sexes & 138 & $81.30^{*}$ & 70 & 0.99 & 0.99 & 0.01 & {$[0.00,0.02]$} \\
\hline 3-(S) + saturation of identical items over time (ST) & 136 & $82.84^{*}$ & 72 & 0.99 & 0.99 & 0.01 & {$[0.00,0.02]$} \\
\hline $4-(\mathrm{S})+(\mathrm{ST})+$ intercepts $(\mathrm{I})$ & 130 & $94.03^{*}$ & 78 & 0.99 & 0.99 & 0.01 & {$[0.00,0.02]$} \\
\hline $5 \mathrm{a}-(\mathrm{S})+(\mathrm{ST})+(\mathrm{I})+$ residual errors $(\mathrm{U})$ of item 2 and 3 are relaxed & 128 & $103.87^{\star}$ & 80 & 0.99 & 0.98 & 0.016 & {$[0.01,0.03]$} \\
\hline $6-(\mathrm{S})+(\mathrm{ST})+(\mathrm{I})+\mathrm{U}+$ correlation of $\mathrm{u}$ of identical items over time (CU) & 125 & $105.16^{\star}$ & 83 & 0.99 & 0.99 & 0.016 & {$[0.00,0.02]$} \\
\hline $7-(\mathrm{S})+(\mathrm{ST})+(\mathrm{I})+\mathrm{U}+(\mathrm{CU})+\operatorname{Var}-\operatorname{cov}(\mathrm{CV})$ & 98 & $158.81^{*}$ & 110 & 0.98 & 0.97 & 0.02 & {$[0.01,0.03]$} \\
\hline $8-(\mathrm{S})+(\mathrm{ST})+(\mathrm{l})+\mathrm{U}+(\mathrm{CU})+(\mathrm{CV})+$ Path & 89 & $202.03^{\star}$ & 119 & 0.97 & 0.96 & 0.03 & {$[0.02,0.03]$} \\
\hline \multicolumn{8}{|l|}{ Model with inattention as mediator } \\
\hline Model with the whole population & 82 & $50.10^{*}$ & 37 & 0.99 & 0.99 & 0.01 & {$[0.00,0.02]$} \\
\hline $4-(\mathrm{S})+(\mathrm{ST})+$ intercepts $(\mathrm{I})$ & 130 & $90.09^{*}$ & 78 & 0.99 & 0.99 & 0.01 & {$[0.00,0.02]$} \\
\hline $5-(\mathrm{S})+(\mathrm{ST})+(\mathrm{I})+$ residual errors $(\mathrm{U})$ & 124 & $118.47^{\star}$ & 84 & 0.99 & 0.99 & 0.02 & {$[0.01,0.03]$} \\
\hline $6-(\mathrm{S})+(\mathrm{ST})+(\mathrm{I})+\mathrm{U}+$ correlation of $\mathrm{u}$ of identical items over time $(\mathrm{CU})$ & 121 & $118.94^{*}$ & 87 & 0.99 & 0.99 & 0.03 & {$[0.01,0.03]$} \\
\hline $7-(\mathrm{S})+(\mathrm{ST})+(\mathrm{I})+\mathrm{U}+(\mathrm{CU})+\operatorname{Var}-\operatorname{cov}(\mathrm{CV})$ & 94 & $176.76^{\star}$ & 114 & 0.99 & 0.99 & 0.03 & {$[0.02,0.03]$} \\
\hline $8-(\mathrm{S})+(\mathrm{ST})+(\mathrm{I})+\mathrm{U}+(\mathrm{CU})+(\mathrm{CV})+$ Path & 85 & $234.15^{\star}$ & 123 & 0.98 & 0.98 & 0.03 & {$[0.02,0.03]$} \\
\hline \multicolumn{8}{|l|}{ Model with frequency of reading as mediator } \\
\hline Model with the whole population & 82 & $67.49^{\star}$ & 37 & 0.98 & 0.96 & 0.02 & {$[0.01,0.03]$} \\
\hline 1-Configural model (sex) & 142 & $104.27^{\star}$ & 66 & 0.98 & 0.96 & 0.02 & {$[0.01,0.03]$} \\
\hline 2-Saturation ( $S$ ) between sexes & 138 & $112.20^{*}$ & 70 & 0.98 & 0.95 & 0.02 & {$[0.02,0.03]$} \\
\hline 3-(S) + saturation of identical items over time (ST) & 136 & $117.47^{\star}$ & 72 & 0.98 & 0.95 & 0.02 & {$[0.02,0.03]$} \\
\hline $4-(\mathrm{S})+(\mathrm{ST})+$ intercepts $(\mathrm{I})$ & 130 & $121.77^{\star}$ & 78 & 0.98 & 0.96 & 0.02 & {$[0.02,0.03]$} \\
\hline 3-(CV) + Path & 72 & $58.82^{*}$ & 36 & 0.97 & 0.95 & 0.02 & {$[0.01,0.04]$} \\
\hline
\end{tabular}

Npar is the number of parameters estimated; $d$ is the degree of freedom; CFI is the "Comparative Fit Index"; TLI is the "Tucker-Lewis Index" and RMSEA is the "Root Mean Square Error of Approximation." *Means that statistically significant at the 5\% level.

\section{Structural Equation Models}

Our statistical analyses were performed with Mplus software (Version 7.4; Muthén and Muthén, 2012) and the results presented are standardized. The four models have been tested with the Maximum Likelihood Robust (MLR) estimator. Only the model that included leisure reading as a mediating variable was fully saturated. For the other three models, which contained latent constructs (interaction with the parent, motivation and inattention), we have correlated the error terms of identical items appearing at several measurement times (Marsh and Hau, 1996). In addition, we have assessed whether these three models fitted the data adequately. To do this, we have selected three indices: the "Comparative Fit Index" (CFI), the "Tucker-Lewis Index" (TLI) and the "Root-Mean-Square Error of Approximation" (RMSEA). Our models were considered well adjusted if the CFI and TLI indices were greater than 0.90 and if the RMSEA was less than 0.08 ( $\mathrm{Hu}$ and Bentler, 1999). We used the "indirect model" procedure to calculate the size of the total and indirect effects (Frazier et al., 2004) of the TV viewing time on the 10year old RA.

\section{Gender Invariance}

In order to test our hypothesis regarding gender, we performed invariance analyses, which consisted in constraining certain parameters of our models to be equal between girls and boys. These analyses were composed of eight models (Caron, 2019) ranging from the unrestricted model (Table 3, line 1) to the most restrictive model (Table 4, line 8). Model 1 did not constrain any parameters across genders. In model 2, factor loadings were constrained to equality across genders. In 
TABLE 4 | Correlations between not answering one of these variables with gender and the PMK diploma ( 0 = answer provided and $1=$ no answer).

\begin{tabular}{|c|c|c|}
\hline & Gender & PMK diploma \\
\hline Parent-child interaction item 1 to 6 years old & -0.06 & -0.10 \\
\hline Parent-child interaction item 2 to 6 years old & -0.07 & -0.12 \\
\hline Parent-child interaction item 3 to 6 years old & -0.06 & -0.10 \\
\hline Parent-child interaction item 1 to 8 years old & -0.07 & -0.12 \\
\hline Parent-child interaction item 2 to 8 years old & -0.06 & -0.10 \\
\hline Parent-child interaction item 3 to 8 years old & -0.07 & -0.12 \\
\hline Inattention item 1 to 7 years old & -0.09 & -0.08 \\
\hline Inattention item 2 to 7 years old & -0.10 & -0.06 \\
\hline Inattention item 3 to 7 years old & -0.09 & -0.08 \\
\hline Inattention item 1 to 8 years old & -0.10 & -0.06 \\
\hline Inattention item 2 to 8 years old & -0.09 & -0.08 \\
\hline Inattention item 3 to 8 years old & -0.10 & -0.05 \\
\hline Leisure reading at 6 years old & -0.09 & -0.15 \\
\hline Leisure reading at 8 years old & -0.07 & -0.10 \\
\hline Intrinsic motivation item 1 to 7 years old & -0.10 & -0.09 \\
\hline Intrinsic motivation item 2 to 7 years old & -0.10 & -0.07 \\
\hline Intrinsic motivation item 3 to 7 years old & -0.10 & -0.09 \\
\hline Intrinsic motivation item 1 to 8 years old & -0.10 & -0.07 \\
\hline Intrinsic motivation item 2 to 8 years old & -0.10 & -0.09 \\
\hline Intrinsic motivation item 3 to 8 years old & -0.10 & -0.07 \\
\hline Reading achievement at 7 years old & -0.09 & -0.07 \\
\hline Reading achievement at 10 years old & -0.06 & -0.09 \\
\hline TV viewing time at 6 years old & -0.06 & -0.09 \\
\hline
\end{tabular}

All correlation coefficients are statistically significant at $p<0.05$.

model 3, factor loadings were constrained to equality across measurement times. Models 2 and 3 offered the possibility to verify if the participants understood items in the same way over time and if gender differences existed in items comprehension. Thereafter, we constrained various parameters including the intercepts (model 4), the residual errors (model 5 ), the correlated uniquenesses (model 6), the variances and covariances (model 7) as well as the paths (model 8). The comparisons among these models were made as follows: when the more restrictive model indicated a decrease of 0.01 in CFI and TLI, but an increase of 0.015 in the RMSEA compared to the less restrictive one (e.g., model 2 vs. model 1 ), the least restrictive model would be considered as better fitting the data.

\section{RESULTS}

\section{Preliminary Analyses Missing Data}

According to Koolstra et al. (1996, 1997), missing data are associated with lesser RA and higher amount of TV viewing. Thus, it was important to adjust for missing data to avoid bias. Among all of our variables, the gender and diploma of the PMK showed little missing data (see Table 2). These two variables allowed us to compare the participants in our sample who had missing data with those who did not. To compare these two

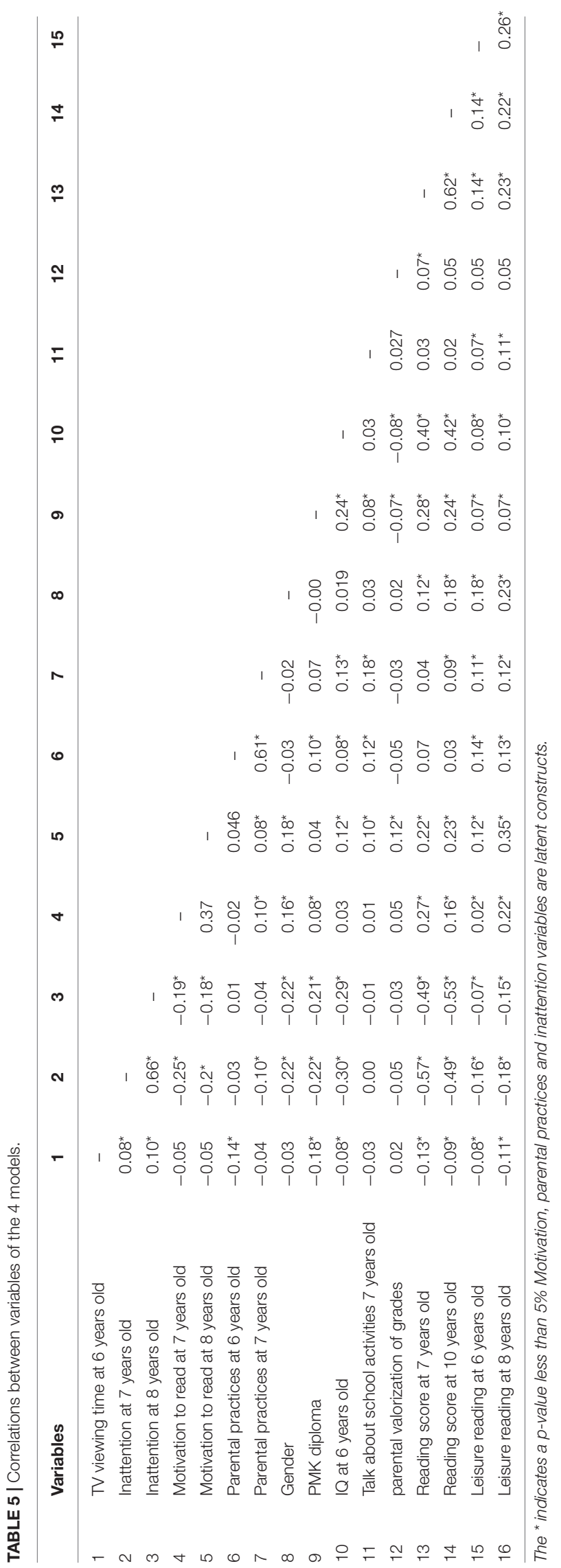


TABLE 6 | All beta and standard error values for the four models (including parameters for covariates).

\begin{tabular}{|c|c|c|c|c|c|c|c|c|c|c|}
\hline \multirow[b]{2}{*}{ Model with inattention as mediator } & \multicolumn{2}{|c|}{$\begin{array}{c}\text { Mediator at } 8 \text { years } \\
\text { old }\end{array}$} & \multicolumn{2}{|c|}{$\begin{array}{c}\text { Reading achievement at } \\
7 \text { years old }\end{array}$} & \multicolumn{2}{|c|}{$\begin{array}{c}\text { Reading achievement at } \\
10 \text { years old }\end{array}$} & \multicolumn{2}{|c|}{$\begin{array}{l}\text { TV viewing time at } \\
6 \text { years old }\end{array}$} & \multicolumn{2}{|c|}{$\begin{array}{c}\text { Mediator at } 7 \text { years } \\
\text { old }\end{array}$} \\
\hline & Beta & SE & Beta & SE & Beta & SE & Beta & SE & Beta & SE \\
\hline TV viewing time at 6 years old & 0.03 & 0.03 & -0.06 & 0.03 & 0.01 & 0.03 & & & 0.03 & 0.03 \\
\hline Inattention at 7 years old & $0.55^{*}$ & 0.03 & & & -0.03 & 0.05 & & & & \\
\hline Inattention at 8 years old & & & & & $-0.25^{\star}$ & 0.04 & & & & \\
\hline Gender $^{a}$ & $-0.11^{\star}$ & 0.03 & 0.03 & 0.02 & $0.07^{*}$ & 0.03 & -0.03 & 0.03 & & \\
\hline PMK diploma & -0.03 & 0.03 & $0.19^{*}$ & 0.03 & 0.03 & 0.03 & $-0.18^{\star}$ & 0.02 & $-0.15^{\star}$ & 0.03 \\
\hline IQ at 6 years old & -0.04 & 0.03 & $0.34^{*}$ & 0.03 & $0.19^{\star}$ & 0.03 & & & $-0.25^{\star}$ & 0.03 \\
\hline Talk about school activities at 7 years old & 0.01 & 0.03 & & & -0.01 & 0.03 & & & & \\
\hline parental valorization of grades at 7 years old & -0.00 & 0.03 & & & 0.03 & 0.03 & & & & \\
\hline Reading achievement at 7 years old & $-0.15^{\star}$ & 0.04 & & & $0.38^{*}$ & 0.03 & & & & \\
\hline \multicolumn{11}{|l|}{ Model with intrinsic motivation as mediator } \\
\hline TV viewing time at 6 years old & -0.02 & 0.03 & $-0.07^{\star}$ & 0.03 & 0.00 & 0.03 & & & -0.04 & 0.03 \\
\hline Intrinsic motivation at 7 years old & $0.32^{*}$ & 0.04 & & & -0.04 & 0.04 & & & & \\
\hline Intrinsic motivation at 8 years old & & & & & $0.09^{*}$ & 0.03 & & & & \\
\hline Gender & $0.13^{\star}$ & 0.03 & $0.09^{\star}$ & 0.03 & $0.10^{*}$ & 0.03 & -0.03 & 0.03 & & \\
\hline PMK diploma & -0.03 & 0.03 & $0.19^{*}$ & 0.03 & 0.05 & 0.03 & $-0.18^{*}$ & 0.02 & $0.07^{*}$ & 0.03 \\
\hline IQ at 6 years old & $0.08^{\star}$ & 0.04 & $0.34^{*}$ & 0.03 & $0.20^{*}$ & 0.03 & & & 0.02 & 0.03 \\
\hline Talk about school activities 7 years old & $0.09^{*}$ & 0.04 & & & -0.02 & 0.03 & & & & \\
\hline parental valorization of grades at 7 years old & $0.09^{*}$ & 0.03 & & & 0.03 & 0.03 & & & & \\
\hline Reading achievement at 7 years old & $0.09^{*}$ & 0.04 & & & $0.50^{*}$ & 0.03 & & & & \\
\hline \multicolumn{11}{|c|}{ Model with frequency of PMK-child interactions as mediator } \\
\hline TV viewing time at 6 years old & 0.04 & 0.04 & $-0.06^{\star}$ & 0.03 & -0.01 & 0.03 & & & & \\
\hline PMK-child interactions at 6 years old & $0.60^{*}$ & 0.05 & 0.01 & 0.04 & -0.09 & 0.05 & & & & \\
\hline PMK-child interactions at 8 years old & & & & & 0.09 & 0.05 & & & & \\
\hline Gender & 0.00 & 0.03 & $0.12^{*}$ & 0.07 & $0.11^{*}$ & 0.03 & -0.03 & 0.03 & -0.03 & 0.04 \\
\hline PMK diploma & -0.01 & 0.04 & $0.19^{\star}$ & 0.03 & 0.05 & 0.03 & $-0.18^{\star}$ & 0.02 & $0.10^{*}$ & 0.04 \\
\hline IQ at 6 years old & $0.10^{\star}$ & 0.04 & $0.34^{\star}$ & 0.03 & $0.20^{*}$ & 0.03 & & & & \\
\hline Talk about school activities 7 years old & $0.11^{*}$ & 0.04 & & & -0.01 & 0.03 & & & & \\
\hline parental valorization of grades at 7 years old & 0.01 & 0.03 & & & 0.03 & 0.03 & & & & \\
\hline Reading achievement at 7 years old & -0.03 & 0.04 & & & $0.51^{*}$ & 0.03 & & & & \\
\hline \multicolumn{11}{|l|}{ Model with leisure reading as mediator } \\
\hline TV viewing time at 6 years old & $-0.07^{\star}$ & 0.03 & -0.05 & 0.03 & 0.07 & 0.03 & & & & \\
\hline Leisure reading at 6 years old & $0.19^{\star}$ & 0.03 & $0.09^{*}$ & 0.03 & 0.01 & 0.03 & & & & \\
\hline Leisure reading at 8 years old & & & & & $0.07^{*}$ & 0.03 & & & & \\
\hline Gender & $0.17^{\star}$ & 0.03 & $0.10^{*}$ & 0.03 & $0.09^{*}$ & 0.03 & -0.03 & 0.03 & $0.18^{*}$ & 0.03 \\
\hline PMK diploma & -0.00 & 0.03 & $0.19^{*}$ & 0.03 & 0.05 & 0.03 & $-0.18^{*}$ & 0.02 & $0.06^{*}$ & 0.03 \\
\hline IQ at 6 years old & 0.01 & 0.03 & $0.33^{*}$ & 0.03 & $0.21^{*}$ & 0.03 & & & & \\
\hline Talk about school activities 7 years old & $0.07^{*}$ & 0.03 & & & -0.02 & 0.03 & & & & \\
\hline parental valorization of grades at 7 years old & 0.03 & 0.03 & & & 0.03 & 0.03 & & & & \\
\hline Reading achievement at 7 years old & $0.16^{*}$ & 0.04 & & & $0.49^{*}$ & 0.03 & & & & \\
\hline
\end{tabular}

*indicates a $p$-value less than $5 \%$

${ }^{a} \mathrm{O}=$ boy and 1 = girl. 


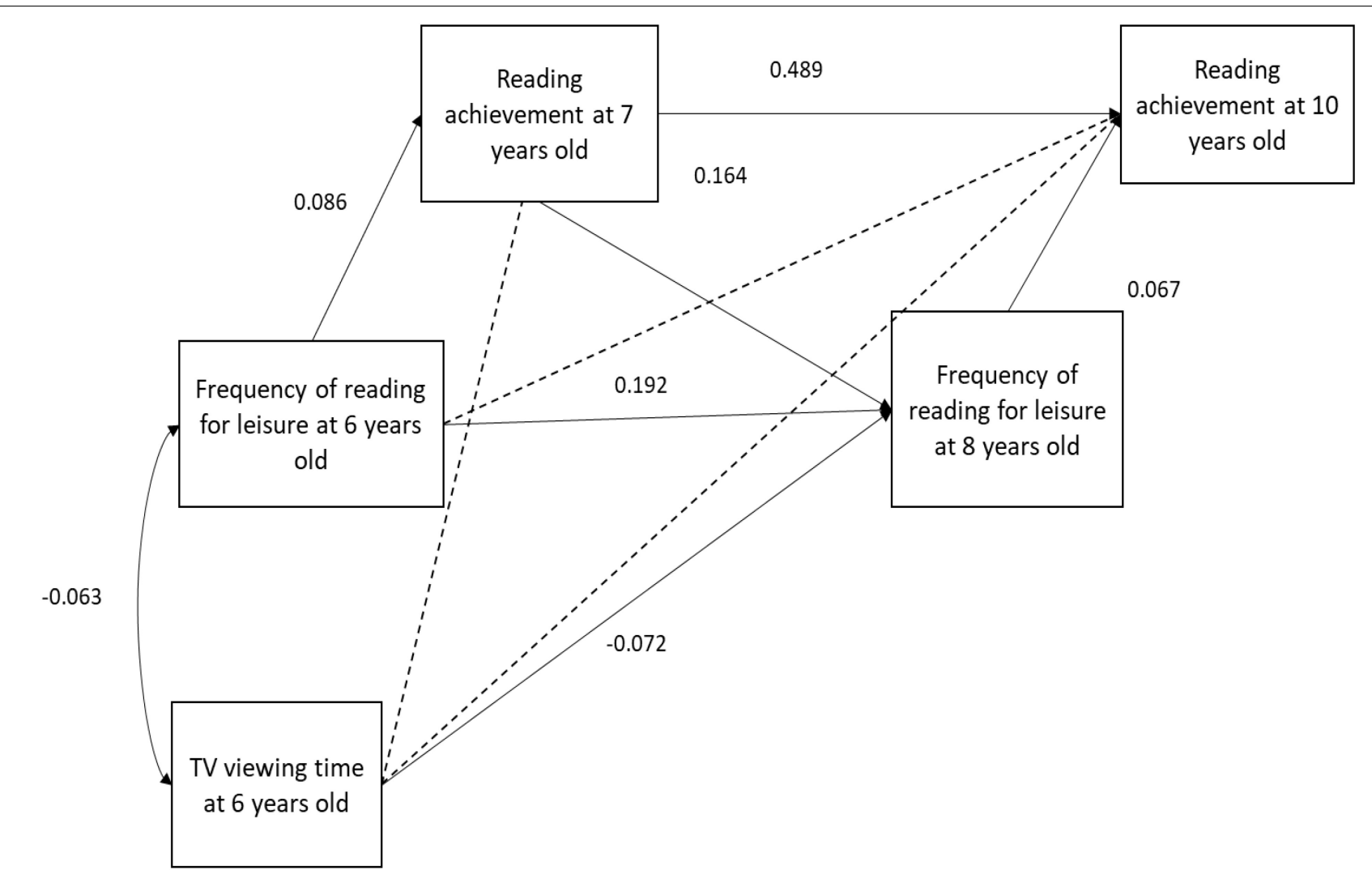

FIGURE 1 | Leisure reading mediation model. Dotted line indicates a $p$-value above 5\%.

subsamples, we first computed a dichotomized score based on responses provided on TV viewing time, RA, IM, leisure reading, inattention and parent-child interaction. Those who had nonmissing scores on these variables were assigned 0 , whereas those who had missing scores were assigned 1. Thus, six dummy variables were computed. Then, we correlated these six dummies to the gender and educational degree of the PMK. Results (see Table 4) indicate that more missing values are observed among boys, $\mathrm{r}$ between -0.052 and -0.104 and children who live in a household where the PMK has a low level of education, $r$ between -0.06 and -0.12 . However, these correlations were quite low.

Thus, the estimation of our models was carried out using the FIML procedure (Muthén and Muthén, 2012), which is a more robust procedure than complete case analysis or imputation with the mean (Caron, 2019). In addition, several participants $(29.8 \%, n=644)$ presented missing data on more than one variable included in our models. We thus tested our models with and without these participants and we did not observe any meaningful difference in the results. For this reason, all participants were kept in our analyses.

\section{Descriptive Statistics}

Table 5 indicates that TV viewing time is statistically significantly associated with RA at 7 and 10 years old, as well as inattention, leisure reading frequency, and the frequency of parent-child interactions at 6 years old. Although statistically significant, all of these relationships were nonetheless very modest. Table 2 shows that, at all measurement times, boys read less frequently for leisure than girls, that they have on average a lower level of IM to read as well as a lower RA. However, there were no gender differences in the average time spent watching TV at 6 years old.

\section{Models Tested \\ Hypothesis Testing}

Table 3 shows the results of the fit indices for the four structural equation models tested. These indices show a very good level of fit because the CFI and TLI values are above 0.95 and the RMSEA values are below 0.025 .

Table 6 presents the beta and the standard error of paths from the four models. Among the covariates, IQ at 6 years old and PMK diploma are the most associated with the mediator variables and the RA variables. In addition, the PMK diploma is the most important predictor of TV viewing time. These results corroborate those of other studies (Koolstra et al., 1997; Ennemoser and Schneider, 2007).

Figures 1-4 present the results of the four models that test the substitution (Figures 1, 2) and inhibition (Figures 3, 4) hypotheses. Among these four models, the only mediator to be associated with TV viewing time was the frequency of leisure reading. More specifically, TV viewing time at 6 years old was negatively associated to leisure reading frequency at 8 years old $(\beta=-0.072 ; \mathrm{SE}=0.033)$. However, this association was too small 


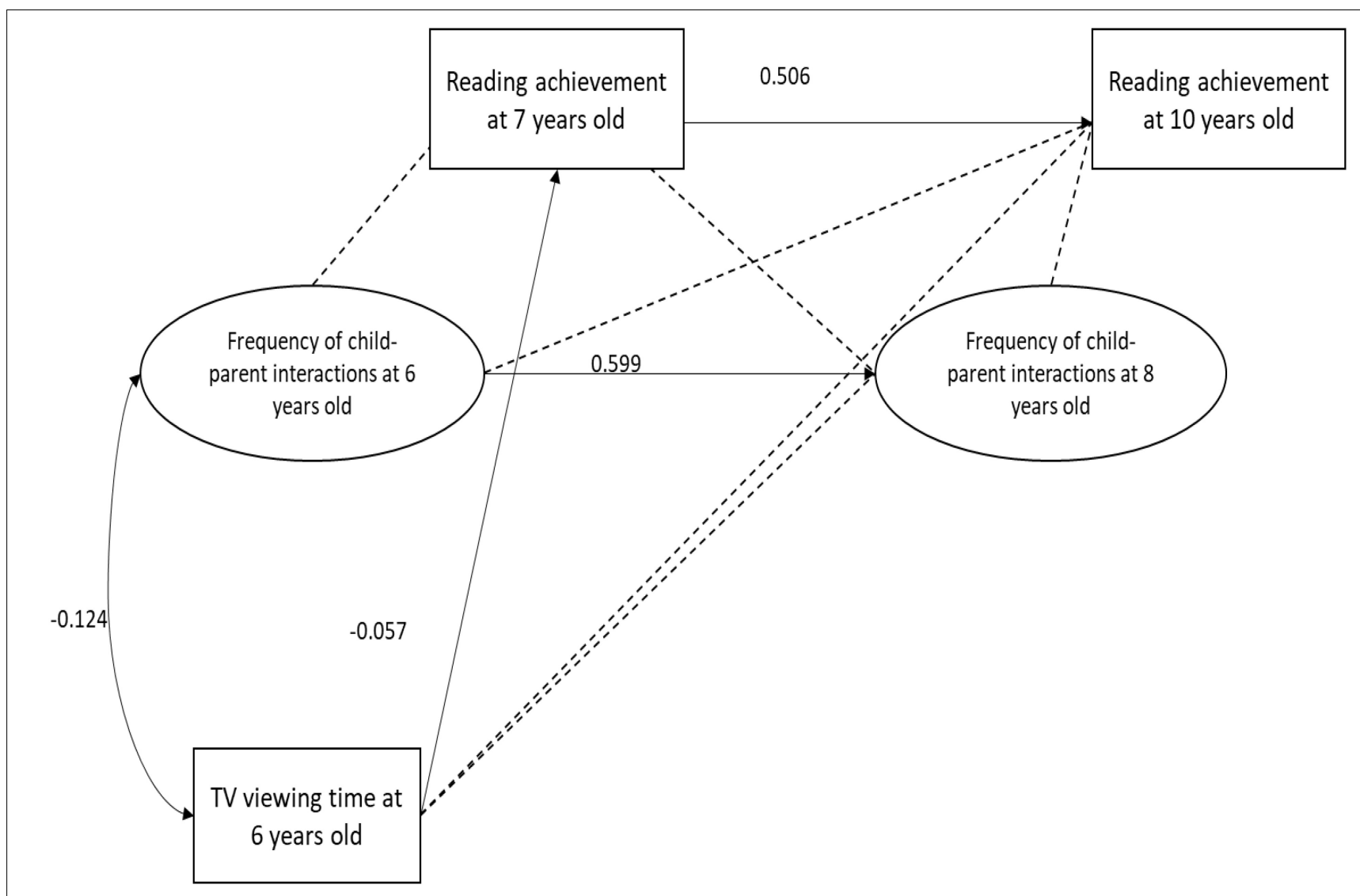

FIGURE 2 | Parent-child interaction mediation model. Dotted line indicates a $p$-value above 5\%.

to produce indirect effects on RA at 10 years old $(\beta=-0.005$; $p=0.117)$.

Table 7, which presents the results of the indirect and total effects, indicates that, with the exception of the parentchild interactions model, the indirect effects of our models are statistically significant, but with small effect sizes ( $\beta$ between -0.036 and -0.032$)$. First, these indirect effects of TV viewing time at 6 years old on RA at 10 years old were caused almost exclusively by the link between TV viewing time and RA at 7 years old. Because these indirect links were not caused by the mediating variables from which we have tested the substitution or inhibition effects, our results therefore did not support the inhibition and substitution hypotheses. Second, there was no statistically significant total effect in the 4 models. This result means that the sum of the direct and indirect effects of the 6 year olds TV viewing time toward the 10 years old RA was not statistically different from zero.

\section{Invariance Analysis}

The results of our invariance analysis indicated that there were no differences between the two groups concerning the associations between the time spent watching TV, our 4 mediators and RA. First, the results of models that tested parent-child attention and interaction as mediators yielded poorer model fit indices (see Table 3). Second, in the model where the IM is the mediator, our results indicate a drop in the acceptable level of the adjustment indices when residual errors are constrained (Table 3, A a q line 5). We therefore removed some of these constraints (see model 5a) and we then constrained the correlated uniquenesses (model 6), the variances and covariances (model 7) as well as the paths (model 8). For model 8, results indicate a little drop in CFI and NNFI values. Thus, we relaxed these constraints and we calculated the differences between genders for the regression coefficients. Our results show small differences between gender for association between IM at 7 years old and motivation at 8 years old, and between TV viewing time at 6 years old and RA at 7 years old. However, there is no difference between genders for associations between TV viewing time at 6 years old and IM at 8 years old and between the TV viewing time at 6 years old and RA at 10 years old (Table 8). Third, in the model where leisure reading is the mediator, our results indicate a decrease in the acceptable level of adjustment indices for the Residual Invariance Model (Table 3, model 2). However, our results do not indicate a further decline in these adjustment indices when the path coefficients are constrained to equality (Table 3 , model 7). Thus, in this model with leisure reading as a mediator, the differences between genders were only found on the variances/covariances and not on the relationship between the time spent watching $\mathrm{TV}$, leisure reading, and RA. In sum, the invariance analysis performed on the four models did not corroborate our second 


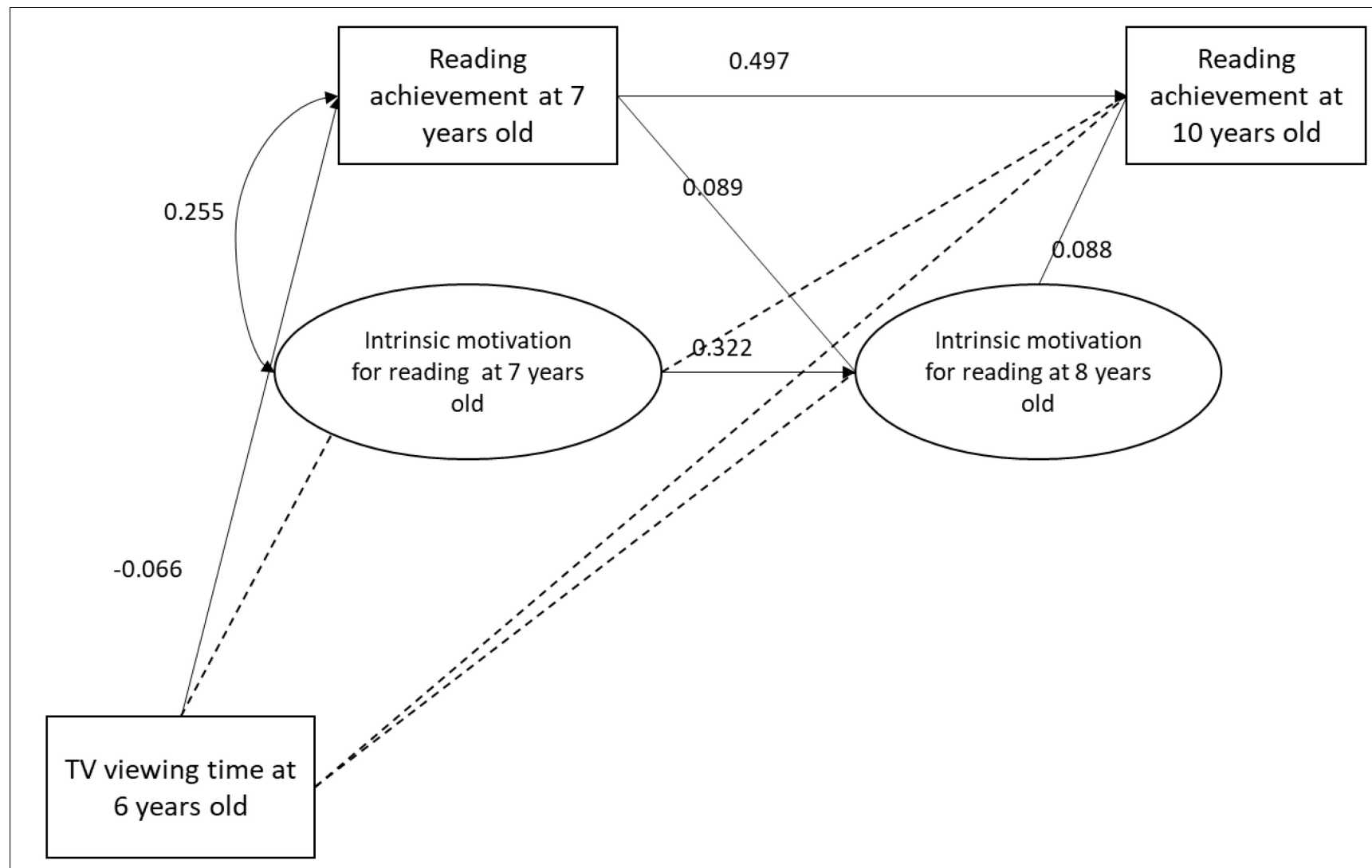

FIGURE 3 | Intrinsic motivation mediation model. Dotted line indicates a $p$-value above 5\%.

hypothesis, which proposed that boys are more exposed than girls to the effects of substitution and inhibition.

\section{DISCUSSION}

The goal of this study was to estimate the contribution of four potential mediating variables (leisure reading, child-parent interaction frequency, IM to read and the level of inattention) explaining the relationship between TV viewing time and RA as a function of gender. These four mediators were chosen to test the substitution and inhibition hypotheses. In addition, we hypothesized that the size of the substitution and inhibition effects would be greater for boys. Overall, our results did not support these assumptions. First, only the leisure reading frequency was negatively associated with TV viewing time at 6 years old, however, this negative association was very small and had no indirect effect on RA at 10 years old. Second, relationships between TV viewing time at 6 years old and our mediating variables at age 9 and RA at age 10 did not vary across genders. Therefore, our results do not corroborate the substitution and inhibition hypotheses, nor do they corroborate our hypothesis proposing that TV viewing would be more detrimental to boys' RA than to the one of girls.

The substitution hypothesis assumes that the time children spend on activities that are favorable to their RA and the time they spend watching TV is organized as a zero-sum game (Peaucelle, 1969). However, our results show, that activities that are favorable to RA are not, or only slightly, replaced by the time that students spend watching TV. One explanation for these results is that children watch TV during times when they probably would not have chosen to perform activities more favorable to their RA. Furthermore, our results also suggest that children practice activities favorable to their RA when they are not permitted to watch TV. For example, children who read at night before sleep when their parents make sure that they cannot watch TV would not see time they spend on this activity decrease if they are more exposed to TV in afternoon. Thus, children who watch more TV are not doing this activity at the expense of the time they spend leisure reading or interacting with their parents.

The inhibition hypothesis is also not corroborated. Specifically, results indicate that there is no association between TV viewing time and IM to read and inattention. A first explanation could be that principles on which the inhibition hypothesis is based are wrong. Specifically, it may be inadequate to propose that TV viewing is a leisure that does not require effort and attention and thus could induce in children "mental laziness". A second possibility is that the negative influence of TV is not important enough to translate into a measurable drop in IM to read and to an increase in inattention symptoms.

Gender moderation analyses did not indicate a difference between the two groups, which does not support our hypothesis. 


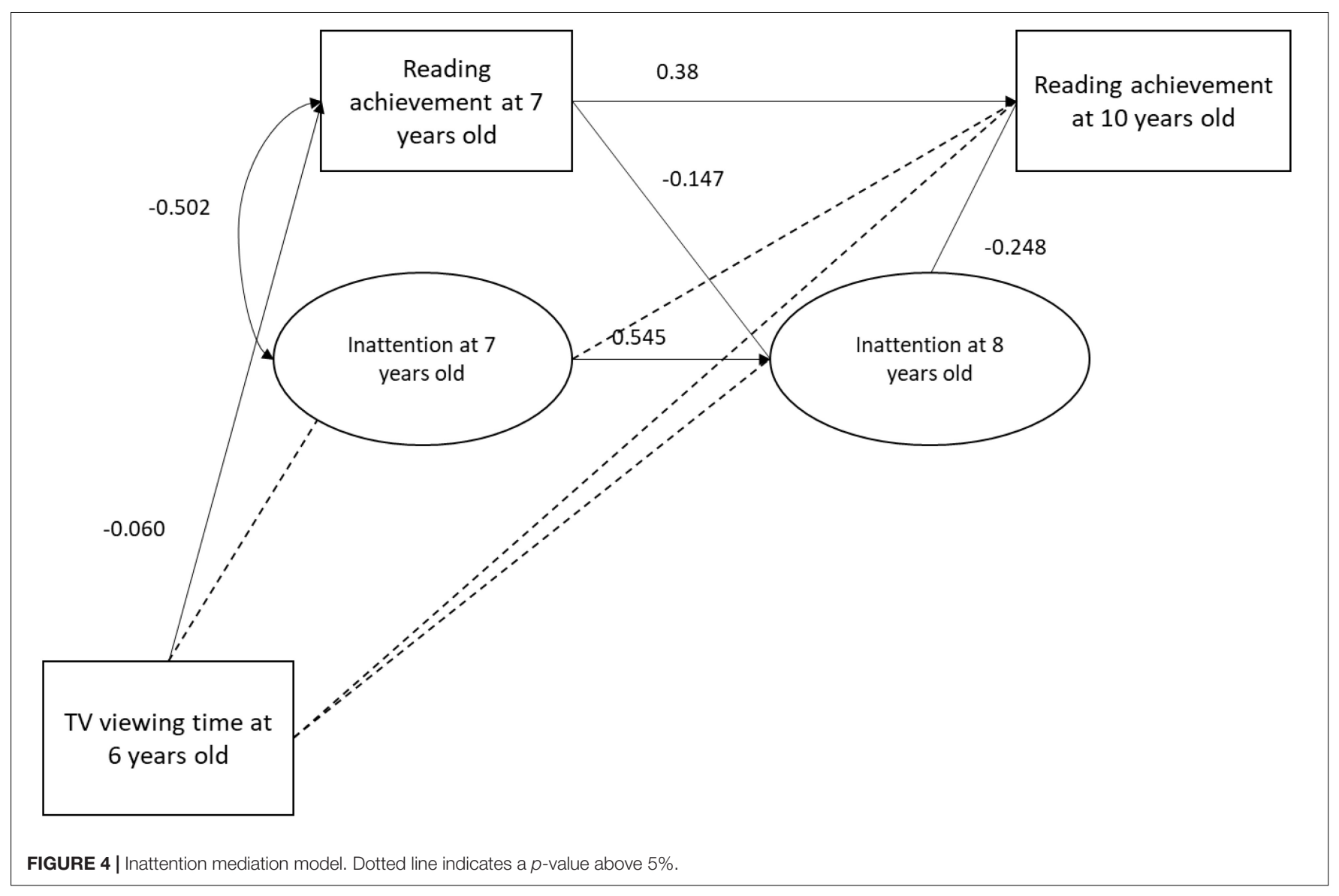

TABLE 7 | Indirect and total effects.

\begin{tabular}{lcccc}
\hline Model & Total effect & $\boldsymbol{p}$-value & Indirect effect & $\boldsymbol{p}$-value \\
\hline Reading & -0.03 & 0.41 & -0.03 & 0.03 \\
Parental practices (PP) & -0.03 & 0.00 & -0.03 & 0.10 \\
Motivation & -0.03 & 0.29 & -0.03 & 0.02 \\
Inattention & -0.03 & 0.34 & -0.04 & 0.03 \\
\hline
\end{tabular}

TABLE 8 | Results of gender differences.

\begin{tabular}{lrcc}
\hline & $\boldsymbol{\beta}$ & Standard error & $\boldsymbol{p}$-value \\
\hline Intrinsic motivation at 8 years old & 0.06 & 0.05 & 0.22 \\
RA at 10 years old & -0.07 & 0.06 & 0.23 \\
\hline
\end{tabular}

This hypothesis is based on the fact that boys and girls have a relationship with reading and TV that differs quantitatively and qualitatively. Our results indicate that, on the contrary, gender does not affect the relationship between TV viewing time, the mediating variables and the RA. As we have suggested, there may be substitution and inhibition moderators that have not been studied yet, such as social and economic status, age of children or the type of content children are watching. In this sense, if gender is not the most relevant moderator, the choice of another moderator should be considered in future studies.

\section{LIMITS}

A first limitation of our study concerns the TV viewing time measure. Indeed, several researchers questioned the accuracy and validity of this measure particularly with regard to the level of measurement error it contains and its relation with social desirability (see Bryant et al., 2007 for a systematic review of these studies from 1985 to 2006; Atkin et al., 2012; CabanasSánchez et al., 2018; Byrne et al., 2021). However, the impact of this shortcoming seems to be trivial for several reasons. Indeed, since the 1980s, the amount of TV viewing time obtained via a self-report measure has been compared to the time derived from objective measures (video or direct observation; see Bryant et al., 2007 for a systematic review of these studies from 1985 to 2006; Clark et al., 2009; Atkin et al., 2012; Cabanas-Sánchez et al., 2018; Aunger and Wagnild, 2020; Byrne et al., 2021). Researchers conclude that self-report questionnaires have an acceptable level of validity (Gorin et al., 2006; Otten et al., 2010; Dwyer et al., 2011; Foley et al., 2012; Wijndaele et al., 2014; Cabanas-Sánchez et al., 2018; Aunger and Wagnild, 2020; De Moraes et al., 2020). Second, the QLSCD comprised a social desirability scale that we used to calculate the correlation with the TV viewing time variable. This correlation is -0.04 . Thus, TV viewing time does not seem to be affected by the degree of social desirability of the participants. Third, Munasib and Bhattacharya (2010) and Nakamuro et al. (2013) measured the impact that measurement error can have 
on the estimation of the relationship between TV viewing time and RA. These authors concluded that measurement error has no impact on results. For these reasons, although it is important to consider that the questionnaire has limitations in measuring TV viewing time, this aspect does not seem to invalidate our results.

Third, the mediating and dependent variables associated with the TV variable are spaced by an interval of two years between each time point. This time interval is imposed by QLSCD sampling. However, it is unknown if and how the duration of time between TV viewing, mediating variables and RA affects effect sizes. To our knowledge, this question of temporality on the link between TV and RA has not yet been studied. Thus, it would be relevant to address this question in further studies.

Fourth, if we have taken into account several important confounding variables, other sources of bias might nevertheless operate. A potential source of bias could come from parents who use TV as a means of reward and punishment (Huang and Lee, 2010). Indeed, this practice consists of increasing the time spent watching TV when children have good grades and decreasing it when children have poor ones. Such contingent use of TV would result in a positive association between TV and RA, that is not mainly attributable to the real effects of TV. However, it seems to us that this risk of bias is relatively low since our TV variable measures the viewing time of children before they enter primary school. Thus, the children in our sample are not subject to a school evaluation that parents could use to regulate their time spent watching TV.

Finally, TV viewing time was measured with 6 years old children. Our results are therefore limited to young children and do not seem to be replicable to an older population such as adolescents. In this regard, no study has tested the substitution and inhibition hypotheses jointly in a population of adolescents. It would therefore be interesting to test these two hypotheses with this population.

\section{CONCLUSION}

The main concerns and criticisms linked to TV viewing are that it replaces reading in children's leisure time, reduces their interest in this activity and increases their inattention, which would harm the development of their competencies at school. However, our results indicate that watching TV is not associated with lower RA and that the drop in the amount of time spent leisure reading is not enough to affect RA. On the social level, our results therefore provide useful input to the debate on TV. Our

\section{REFERENCES}

Acevedo-Polakovich, I. D., Lorch, E. P., Milich, R., and Ashby, R. D. (2006). Disentangling the relation between television viewing and cognitive processes in children with attention-deficit/hyperactivity disorder and comparison children. Arch. Pediatr. Adolesc. Med. 160, 354-360.

Anderson, D., Huston, A., Schmitt, K., Linebarger, D., Wright, J., and Larson, R. (2001). Early childhood television viewing and adolescent behavior: the Recontact Study. Monogr. Soc. Res. Child Dev. 66, I-154. doi: 10.1111/15405834.00124 results do not support the substitution and inhibition hypotheses while controlling for important covariates. However, it seems wrong to consider that these results completely invalidate these two hypotheses for three reasons.

First, the research that has tested these two hypotheses presents mixed results. If some studies obtained results similar to ours, indicating that the time spent watching TV is very weakly and negatively associated with the time spent leisure reading (Koolstra et al., 1996; Ennemoser and Schneider, 2007) and that it is not associated with IM to read and inattention (Ansari and Crosnoe, 2016), other studies have shown different results (Ritchie et al., 1987; Koolstra et al., 1996; Anderson et al., 2001; Wright et al., 2001; Zimmerman et al., 2007). Our results should therefore be interpreted with caution.

Second, there is an increasing presence of new types of screens such as digital tablets, telephones or laptops (Kostyrka-Allchorne et al., 2017). These screens present major differences when compared to TV. Unlike a fixed screen, they allow the viewers to access a large variety of content easily and quickly, right in the palm of their hands, anywhere, anytime. Thus, it seems important to test the substitution and inhibition hypotheses in this context of new screens. Considering that watching TV shows is one of the main activities that children perform with these screens (Rideout, 2016) and considering that there is still little research on our subject, it therefore seems socially and scientifically important to emphasize the need to undertake additional studies in order to have a more substantiated knowledge on the relationship between exposure to TV or streaming programs, children's RA and the mediators and moderators likely to explain that relation.

\section{DATA AVAILABILITY STATEMENT}

Publicly available datasets were analyzed in this study. This data can be found here: https://www.jesuisjeserai.stat.gouv.qc.ca/ default_an.htm.

\section{AUTHOR CONTRIBUTIONS}

WS conducted the study process, performed data analysis, and drafted the manuscript. FG supervised the design of the study. FG and DT contributed to the data analysis and results interpretation, critically revised the article, and approved this version. All authors provided important contributions to the work.

Ansari, A., and Crosnoe, R. (2016). Children's hyperactivity, television viewing, and the potential for child effects. Child. Youth Serv. Rev. 61, 135-140. doi: 10.1016/j.childyouth.2015.12.018

Atkin, A. J., Gorely, T., Clemes, S. A., Yates, T., Edwardson, C., Brage, S., et al. (2012). Methods of measurement in epidemiology: sedentary behaviour. Int. J. Epidemiol. 41, 1460-1471. doi: 10.1093/ije/dys118

Aunger, J., and Wagnild, J. (2020). Objective and subjective measurement of sedentary behavior in human adults: a toolkit. Am. J. Hum. Biol. e23546. doi: 10.1002/ajhb.23546 [Epub ahead of print].

Barr, R., Lauricella, A., Zack, E., and Calvert, S. L. (2010). Infant and early childhood exposure to adult-directed and child-directed television 
programming: relations with cognitive skills at age four. Merrill Palmer Q. 56, 21-48. doi: 10.1353/mpq.0.0038

Beentjes, J. W., and Van der Voort, T. H. (1988). Television's impact on children's reading. Read. Res. Q. 23, 389-413. doi: 10.2307/747640

Bergin, D. A. (1992). Leisure activity, motivation, and academic achievement in high school students. J. Leis. Res. 24, 225-239. doi: 10.1080/00222216.1992. 11969890

Bittman, M., Rutherford, L., Brown, J., and Unsworth, L. (2011). Digital natives? New and Old Media and Children's Outcomes. Aust. J. Educ. 55, 161-175. doi: 10.1177/000494411105500206

Blankson, A. N., O’Brien, M., Leerkes, E. M., Calkins, S. D., and Marcovitch, S. (2015). Do hours spent viewing television at ages 3 and 4 predict vocabulary and executive functioning at age 5? Merrill Palmer Q. 61, 264-289. doi: 10. 13110/merrpalmquar1982.61.2.0264

Boivin, M., Pérusse, D., Saysset, V., Tremblay, N., and Tremblay, R. (2000). Conduites Parentales et Relations Familiales, Section I-Les Cognitions et les Conduites Parentales. Étude Longitudinale du Développement des Enfants du Québec (ÉLDEQ 1998-2002). Available online at: https://bdso.gouv.qc.ca/docsken/multimedia/PB01671FR_ELDEQ_vol1no10_2001H00F02.pdf (accessed October 01, 2021).

Boyle, M. H., Offord, D. R., Racine, Y., Sanford, M., Szatmari, P., and Fleming, J. E. (1993). Evaluation of the original Ontario child health study scales. Can. J. Psychiatry 38, 397-405. doi: 10.1177/070674379303800605

Bryant, M. J., Lucove, J. C., Evenson, K. R., and Marshall, S. (2007). Measurement of television viewing in children and adolescents: a systematic review. Obes. Rev. 8, 197-209. doi: 10.1111/j.1467-789X.2006.00295.x

Byrne, R., Terranova, C. O., and Trost, S. G. (2021). Measurement of screen time among young children aged 0-6 years: a systematic review. Obes. Rev. 22:e13260. doi: 10.1111/obr.13260

Cabanas-Sánchez, V., Martínez-Gómez, D., Esteban-Cornejo, I., Castro-Piñero, J., Conde-Caveda, J., and Veiga, Ó. L. (2018). Reliability and validity of the youth leisure-time sedentary behavior questionnaire (YLSBQ). J. Sci. Med. Sport 21, 69-74. doi: 10.1016/j.jsams.2017.10.031

Cardin, J.-F., Desrosiers, H., Belleau, L., Giguère, C., and Boivin, M. (2011). Les Symptômes D'Hyperactivité et d'Inattention chez les Enfants de la Période Préscolaire à la Deuxième Année du Primaire. Portraits et trajectoires. Série Étude longitudinale du développement des enfants du Québec-ÉLDEQ. Available online at: https://bdso.gouv.qc.ca/docs-ken/multimedia/PB01671FR_ hyperactivite2010H00F00.pdf (accessed October 01, 2021).

Caron, P.-O. (2019). La Modélisation par Équations Structurelles avec Mplus. Québec: PUQ. doi: 10.2307/j.ctvt1sh9g

Cheng, S., Maeda, T., Yoichi, S., Yamagata, Z., Tomiwa, K., and Group, J. C. S. (2010). Early television exposure and children's behavioral and social outcomes at age 30 months. J. Epidemiol. 20, S482-S489. doi: 10.2188/jea.JE2009 0179

Childers, J. S., Durham, T. W., and Wilson, S. (1994). Relation of Performance on the Kaufman Brief Intelligence Test with the Peabody Picture Vocabulary Test-Revised among Preschool Children. Percept. Mot. Skills 79, 1195-1199. doi: 10.2466/pms.1994.79.3.1195

Christakis, D. A., Zimmerman, F. J., DiGiuseppe, D. L., and McCarty, C. A. (2004). Early television exposure and subsequent attentional problems in children. Pediatrics 113, 708-713. doi: 10.1542/peds.113.4.708

Clark, B. K., Sugiyama, T., Healy, G. N., Salmon, J., Dunstan, D. W., and Owen, N. (2009). Validity and reliability of measures of television viewing time and other non-occupational sedentary behaviour of adults: a review. Obes. Rev. 10, 7-16. doi: 10.1111/j.1467-789X.2008.00508.x

Clark, C. (2012). Children's and Young People's Reading Today: Findings from the 2011 National Literacy Trust's Annual Survey. London: National Literacy Trust.

Coyne, S. M., Linder, J. R., Rasmussen, E. E., Nelson, D. A., and Collier, K. M. (2014). It's a bird! It's a plane! It's a gender stereotype!: longitudinal associations between superhero viewing and gender stereotyped play. Sex Roles 70, 416-430. doi: 10.1007/s11199-014-0374-8

De Moraes, A. C. F., Nascimento-Ferreira, M. V., de Moraes Forjaz, C. L., RAistizabal, J. C., Azzaretti, L., Junior, W. V. N., et al. (2020). Reliability and validity of a sedentary behavior questionnaire for South American pediatric population: SAYCARE study. BMC Med. Res. Methodol. 20:5. doi: 10.1186/ s12874-019-0893-7
Desmurget, M. (2011). Tv Lobotomie: La Vérité Scientifique sur les Effets de la Télévision. Paris: Max Milo.

Duch, H., Fisher, E. M., Ensari, I., Font, M., Harrington, A., Taromino, C., et al. (2013). Association of Screen Time Use and Language Development in Hispanic Toddlers: A Cross-Sectional and Longitudinal Study. Clin. Pediatr. 52, 857-865. doi: 10.1177/0009922813492881

Dunn, L. M., Dunn, L. M., and Thériault-Whalen, C. M. (1993). Échelle de Vocabulaire en Images Peabody: EVIP. Toronto: Psycan.

Dwyer, G. M., Hardy, L. L., Peat, J. K., and Baur, L. A. (2011). The validity and reliability of a home environment preschool-age physical activity questionnaire (Pre-PAQ). Int. J. Behav. Nutr. Phys. Act. 8, 1-13. doi: 10.1186/1479-58 68-8-86

Ennemoser, M., and Schneider, W. (2007). Relations of television viewing and reading: findings from a 4-year longitudinal study. J. Educ. Psychol. 99, 349-368. doi: 10.1037/0022-0663.99.2.349

Foley, L., Maddison, R., Olds, T., and Ridley, K. (2012). Self-report use-of-time tools for the assessment of physical activity and sedentary behaviour in young people: systematic review. Obes. Rev. 13, 711-722. doi: 10.1111/j.1467-789X. 2012.00993.x

Forget-Dubois, N., Lemelin, J.-P., Boivin, M., Dionne, G., Séguin, J. R., Vitaro, F., et al. (2007). Predicting early school achievement with the EDI: a longitudinal population-based study. Early Educ. Dev. 18, 405-426. doi: 10. 1080/10409280701610796

Foster, E. M., and Watkins, S. (2010). The value of reanalysis: TV viewing and attention problems. Child Dev. 81, 368-375. doi: 10.1111/j.1467-8624.2009. 01400.x

Frazier, P. A., Tix, A. P., and Barron, K. E. (2004). Testing moderator and mediator effects in counseling psychology research. J. Couns. Psychol. 51, 115-134. doi: 10.1037/0022-0167.51.1.115

Gentzkow, M., and Shapiro, J. M. (2008). Preschool television viewing and adolescent test scores: historical evidence from the Coleman study. Q. J. Econ. 123, 279-323. doi: 10.1162/qjec.2008.123.1.279

Gorin, A., Raynor, H., Chula-Maguire, K., and Wing, R. (2006). Decreasing household television time: a pilot study of a combined behavioral and environmental intervention. Behav. Interv. 21, 273-280. doi: 10.1002/ bin. 221

Guay, F., Chanal, J., Ratelle, C. F., Marsh, H. W., Larose, S., and Boivin, M. (2010). Intrinsic, identified, and controlled types of motivation for school subjects in young elementary school children. Br. J. Educ. Psychol. 80, 711-735. doi: 10.1348/000709910X499084

Guay, F., Larose, S., Ratelle, C., Sénécal, C., Vallerand, R. J., and Vitaro, F. (2007). Mes Amis, mes Parents et mes Professeurs: Une Analyse Comparée de leurs Effets Respectifs sur la Motivation, la Réussite, Lorientation et la Persévérance Scolaires. Québec: Université de Laval.

Guthrie, J. T., Wigfield, A., and You, W. (2012). "Instructional contexts for engagement and achievement in reading," in Handbook of Research on Student Engagement, eds S. J. Christenson, A. L. Reschly and C. Wylie (Boston, MA: Springer), 601-634. doi: 10.1007/978-1-4614-2018-7_29

Hamer, M., Stamatakis, E., and Mishra, G. D. (2010). Television-and screen-based activity and mental well-being in adults. Am. J. Prev. Med. 38, 375-380. doi: 10.1016/j.amepre.2009.12.030

Himmelweit, H. T., Oppenheim, A. N., and Vince, P. (1958). Television and the Child. Oxford: Oxford University Press.

Hornik, R. (1981). Out-of-school television and schooling: hypotheses and methods. Rev. Educ. Res. 51, 193-214. doi: 10.3102/00346543051002193

Hu, L. T., and Bentler, P. M. (1999). Cutoff criteria for fit indexes in covariance structure analysis: conventional criteria versus new alternatives. Struct. Equ. Model. 6, 1-55. doi: 10.1080/10705519909540118

Huang, F., and Lee, M. J. (2010). Dynamic treatment effect analysis of TV effects on child cognitive development. J. Appl. Econ. 25, 392-419. doi: 10.1002/jae.1165

Jetté, M., and Des Groseilliers, L. (2000). L'enquête: Description et Méthodologie dans Étude Longitudinale du Développement des Enfants du Québec (ÉLDEQ 1998-2002). Québec: Institut de la statistique du Québec.

Johnson, J. G., Cohen, P., Kasen, S., and Brook, J. S. (2007). Extensive television viewing and the development of attention and learning difficulties during adolescence. Arch. Pediatr. Adolesc. Med. 161, 480-486. doi: 10.1001/archpedi. 161.5.480 
Koolstra, C. M., Voort, T. H., and Kamp, L. J. T. (1997). Television's Impact on Children's Reading Comprehension and Decoding Skills: a 3-Year Panel Study. Read. Res. Q. 32, 128-152. doi: 10.1598/RRQ.32.2.1

Koolstra, C. M., Voort, T. H., and Voort, D. (1996). Longitudinal effects of television on Children's Leisure-time reading a test of three explanatory models. Hum. Commun. Res. 23, 4-35.

Kostyrka-Allchorne, K., Cooper, N. R., and Simpson, A. (2017). The relationship between television exposure and children's cognition and behaviour: a systematic review. Dev. Rev. 44, 19-58. doi: 10.1016/j.dr.2016.12.002

Landhuis, C. E., Poulton, R., Welch, D., and Hancox, R. J. (2007). Does childhood television viewing lead to attention problems in adolescence? Results from a prospective longitudinal study. Pediatrics 120, 532-537. doi: 10.1542/peds. 2007-0978

Linebarger, D. L., and Walker, D. (2005). Infants' and toddlers' television viewing and language outcomes. Am. Behav. Sci. 48, 624-645. doi: 10.1177/ 0002764204271505

Lonner, W. J., Thorndike, R. M., Forbes, N. E., and Ashworth, C. (1985). The influence of television on measured cognitive abilities: a study with Native Alaskan children. J. Cross Cult. Psychol. 16, 355-380. doi: 10.1177/ 0022002185016003006

Maass, E. E., Hahlweg, K., Heinrichs, N., Kuschel, A., and Doepfner, M. (2010). Screen media in preschool age: on the relationship between media use, behavior problems, and ADHD. Eur. J. Health Psychol. 18, 55-68. doi: 10.1026/0943$8149 /$ a000009

Malanchini, M., Wang, Z., Voronin, I., Schenker, V. J., Plomin, R., Petrill, S. A., et al. (2017). Reading self-perceived ability, enjoyment and achievement: a genetically informative study of their reciprocal links over time. Dev. Psychol. 53, 698-712. doi: 10.1037/dev0000209

Manu, M., Torppa, M., Eklund, K., Poikkeus, A. M., Lerkkanen, M. K., and Niemi, P. (2021). Kindergarten pre-reading skills predict Grade 9 reading comprehension (PISA Reading) but fail to explain gender difference. Read. Writ. 34, 753-771. doi: 10.1007/s11145-020-10090-w

Marsh, H. W., and Hau, K.-T. (1996). Assessing goodness of fit: Is parsimony always desirable? J. Exp. Educ. 64, 364-390. doi: 10.1080/00220973.1996. 10806604

Mehmet-Radji, O. (2004). Early television exposure and subsequent attentional problems in children. Child Care Health Dev. 30, 559-560. doi: 10.1111/j.13652214.2004.00456_4.x

Miller, C. J., Marks, D. J., Miller, S. R., Berwid, O. G., Kera, E. C., Santra, A., et al. (2007). Brief Report: television viewing and risk for attention problems in preschool children. J. Pediatr. Psychol. 32, 448-452. doi: 10.1093/jpepsy/jsl035

Morgan, P. L., and Fuchs, D. (2007). Is There a Bidirectional Relationship between Children's Reading Skills and Reading Motivation? Except. Child. 73, 165-183. doi: 10.1177/001440290707300203

Morin, M.-F. (2014). Portrait du Jeune Lecteur Québécois de la 1re Année du Primaire à la 5e Année du Secondaire. Rapport Final. Québec: Université de Sherbrooke.

Munasib, A., and Bhattacharya, S. (2010). Is the 'Idiot's Box' raising idiocy? Early and middle childhood television watching and child cognitive outcome. Econ. Educ. Rev. 29, 873-883. doi: 10.1016/j.econedurev.2010.03.005

Muthén, L. K., and Muthén, B. O. (2012). Mplus Version 7 User's Guide. Los Angeles, CA: Muthén \& Muthén.

Nakamuro, M., Matsuoka, R., and Inui, T. (2013). More Time Spent on Television and Video Games, Less Time Spent Studying? Discussion Papers (by fiscal year), 2012, 2011. Tokyo: Research Institute of Economy, Trade and Industry.

Nanhou, V., Desrosiers, H., Tétreault, K., and Guay, F. (2016). La Motivation en Lecture Durant L'enfance et le Rendement Dans la Langue D'enseignement à 15 ans. Québec: Institut de la statistique du Québec.

Otten, J. J., Littenberg, B., and Harvey-Berino, J. R. (2010). Relationship between self-report and an objective measure of television-viewing time in adults. Obesity 18, 1273-1275. doi: 10.1038/oby.2009.371

Pagani, L. S., Fitzpatrick, C., and Barnett, T. A. (2013). Early childhood television viewing and kindergarten entry readiness. Pediatr. Res. 74, 350-355. doi: 10. 1038/pr.2013.105

Paik, H. (2000). Television viewing and high school mathematics achievement: a neural network analysis. Qual. Quant. 34, 1-15. doi: 10.1023/A:1004795407624

Parkes, A., Sweeting, H., Wight, D., and Henderson, M. (2013). Do television and electronic games predict children's psychosocial adjustment? Longitudinal research using the UK Millennium Cohort Study. Arch. Dis. Child. 98, 341-348. doi: 10.1136/archdischild-2011-301508

Peaucelle, J.-L. (1969). Théorie des jeux et sociologie des organisations. Sociol. Travail 11, 22-43. doi: 10.3406/sotra.1969.1410

Pingault, J.-B., Côté, S. M., Galéra, C., Genolini, C., Falissard, B., Vitaro, F., et al. (2013). Childhood trajectories of inattention, hyperactivity and oppositional behaviors and prediction of substance abuse/dependence: a 15year longitudinal population-based study. Mol. Psychiatry 18:806812. doi: 10. 1038/mp.2012.87

Popper, K. R., Condry, J., Orsoni, C., Bosetti, G., and Baudouin, J. (1995). La télévision, Un Danger Pour la Démocratie. Réseaux 13, 201-204.

Postman, N. (1986). Amusing Ourselves to Death: Public Discourse in the Age of Show Business. New York, NY: Penguin Books.

Rabiner, D., Coie, J. D., and Group, C. P. P. R. (2000). Early attention problems and children's reading achievement: a longitudinal investigation. J. Am. Acad. Child Adolesc. Psychiatry 39, 859-867. doi: 10.1097/00004583-200007000-00014

Razel, M. (2001). The complex model of television viewing and educational achievement. J. Educ. Res. 94, 371-379. doi: 10.1080/00220670109598774

Rideout, V. (2016). Measuring time spent with media: the Common Sense census of media use by US 8-to 18-year-olds. J. Child. Media 10, 138-144. doi: 10.1080/ 17482798.2016.1129808

Ritchie, D., Price, V., and Roberts, D. F. (1987). Television, reading, and reading achievement a reappraisal. Commun. Res. 14, 292-315. doi: 10.1177/ 009365087014003002

Romano, E., Tremblay, R. E., Farhat, A., and Côté, S. (2006). Development and prediction of hyperactive symptoms from 2 to 7 years in a population-based sample. Pediatrics 117, 2101-2110. doi: 10.1542/peds.2005-0651

Ruangdaraganon, N., Chuthapisith, J., Mo-suwan, L., Kriweradechachai, S., Udomsubpayakul, U., and Choprapawon, C. (2009). Television viewing in Thai infants and toddlers: impacts to language development and parental perceptions. BMC Pediatr. 9:34. doi: 10.1186/1471-2431-9-34

Ryan, R. M., and Deci, E. L. (2000). Self-determination theory and the facilitation of intrinsic motivation, social development, and well-being. Am. Psychol. 55, 68-78. doi: 10.1037/0003-066X.55.1.68

Salla, J., Michel, G., Pingault, J. B., Lacourse, E., Paquin, S., Galéra, C., et al. (2016). Childhood trajectories of inattention-hyperactivity and academic achievement at 12 years. Eur. Child Adolesc. Psychiatry 25, 1195-1206. doi: 10.1007/s00787016-0843-4

Schmidt, M. E., Rich, M., Rifas-Shiman, S. L., Oken, E., and Taveras, E. M. (2009). Television viewing in infancy and child cognition at 3 years of age in a US Cohort. Pediatrics 123, e370-e375. doi: 10.1542/peds.2008-3221

Schmiedeler, S., Niklas, F., and Schneider, W. (2014). Symptoms of attentiondeficit hyperactivity disorder (ADHD) and home learning environment (HLE): findings from a longitudinal study. Eur. J. Psychol. Educ. 29, 467-482. doi: 10.1007/s10212-013-0208-z

Schramm, W. (1961). Television in the Lives of Our Children. Palo Alto, CA: Stanford University Press.

Sharif, I., Wills, T. A., and Sargent, J. D. (2010). Effect of visual media use on school performance: a prospective study. J. Adolesc. Health 46, 52-61. doi: 10.1016/j.jadohealth.2009.05.012

Shin, N. (2004). Exploring pathways from television viewing to academic achievement in school age children. J. Genet. Psychol. 165, 367-382. doi: 10. 3200/GNTP.165.4.367-382

Sisson, S. B., Shay, C. M., Broyles, S. T., and Leyva, M. (2012). Television-viewing time and dietary quality among US children and adults. Am. J. Prev. Med. 43, 196-200. doi: 10.1016/j.amepre.2012.04.016

Stevens, T., Barnard-Brak, L., and To, Y. (2009). Television viewing and symptoms of inattention and hyperactivity across time: the importance of research questions. J. Early Interv. 31, 215-226. doi: 10.1177/1053815109338562

Stevens, T., and Mulsow, M. (2006). There is no meaningful relationship between television exposure and symptoms of attention-deficit/hyperactivity disorder. Pediatrics 117, 665-672. doi: 10.1542/peds.2005-0863

Strayhorn, J. M., and Weidman, C. S. (1988). A parent practices scale and its relation to parent and child mental health. J. Am. Acad. Child Adolesc. Psychiatry 27, 613-618. doi: 10.1097/00004583-198809000-00016

Supper, W., Talbot, D., and Guay, F. (2021). Association entre le temps d'écoute de la télévision et le rendement scolaire des enfants et des adolescents: recension 
systématique et méta-analyse des études longitudinales réalisées à ce jour. Can J. Behav. Sci. doi: 10.1037/cbs0000275

Swing, E. L., Gentile, D. A., Anderson, C. A., and Walsh, D. A. (2010). Television and video game exposure and the development of attention problems. Pediatrics 126, 214-221. doi: 10.1542/peds.2009-1508

Tétreault, K., and Desrosiers, H. (2014). Les Facteurs liés à la Réussite à Lépreuve Obligatoire de Mathématique en Sixième Année du Primaire: Un tour D’horizon. Observatoire de la Culture et des Communications. Québec: Institut de la statistique du Québec.

Tomopoulos, S., Dreyer, B. P., Berkule, S., Fierman, A. H., Brockmeyer, C., and Mendelsohn, A. L. (2010). Infant media exposure and toddler development. Arch. Pediatr. Adolesc. Med. 164, 1105-1111. doi: 10.1001/archpediatrics.2010. 235

Torppa, M., Niemi, P., Vasalampi, K., Lerkkanen, M. K., Tolvanen, A., and Poikkeus, A. M. (2020). Leisure reading (but not any kind) and reading comprehension support each other-A longitudinal study across grades 1 and 9. Child Dev. 91, 876-900. doi: 10.1111/cdev.13241

Verhoeven, M., Junger, M., van Aken, C., Deković, M., and van Aken, M. A. (2010). Parenting and children's externalizing behavior: bidirectionality during toddlerhood. J. Appl. Dev. Psychol. 31, 93-105. doi: 10.1016/j.appdev.2009.09. 002

Wijndaele, K., De Bourdeaudhuij, I., Godino, J. G., Lynch, B. M., Griffin, S. J., Westgate, K., et al. (2014). Reliability and validity of a domain-specific last 7d sedentary time questionnaire. Med. Sci. Sports Exerc. 46, 1248-1260. doi: 10.1249/MSS.0000000000000214

Winn, M. (1977). The Plug-in Drug. New York, NY: Viking Penguin.

Wright, J. C., Huston, A. C., Murphy, K. C., St Peters, M., Piñon, M., Scantlin, R., et al. (2001). The relations of early television viewing to school readiness and vocabulary of children from low-income families: the early window project. Child Dev. 72, 1347-1366. doi: 10.1111/1467-8624.t01-1-00352

Zavodny, M. (2006). Does watching television rot your mind? Estimates of the effect on test scores. Econ. Educ. Rev. 25, 565-573. doi: 10.1016/j.econedurev. 2005.08.003
Zimmerman, F. J., and Christakis, D. A. (2005). Children's television viewing and cognitive outcomes: a longitudinal analysis of national data. Arch. Pediatr. Adolesc. Med. 159, 619-625. doi: 10.1001/archpedi.159. 7.619

Zimmerman, F. J., and Christakis, D. A. (2007). Associations between content types of early media exposure and subsequent attentional problems. Pediatrics 120, 986-992. doi: 10.1542/peds.2006-3322

Zimmerman, F. J., Christakis, D. A., and Meltzoff, A. N. (2007). Associations between media viewing and language development in children under age 2 years. J. Pediatr. 151, 364-368. doi: 10.1016/j.jpeds.2007. 04.071

Zimmerman, F. J., Gilkerson, J., Richards, J. A., Christakis, D. A., Xu, D., Gray, S., et al. (2009). Teaching by listening: the importance of adult-child conversations to language development. Pediatrics 124, 342-349. doi: 10.1542/peds.20082267

Conflict of Interest: The authors declare that the research was conducted in the absence of any commercial or financial relationships that could be construed as a potential conflict of interest.

Publisher's Note: All claims expressed in this article are solely those of the authors and do not necessarily represent those of their affiliated organizations, or those of the publisher, the editors and the reviewers. Any product that may be evaluated in this article, or claim that may be made by its manufacturer, is not guaranteed or endorsed by the publisher.

Copyright (c) 2021 Supper, Guay and Talbot. This is an open-access article distributed under the terms of the Creative Commons Attribution License (CC BY). The use, distribution or reproduction in other forums is permitted, provided the original author(s) and the copyright owner(s) are credited and that the original publication in this journal is cited, in accordance with accepted academic practice. No use, distribution or reproduction is permitted which does not comply with these terms. 